\title{
Briquetting the Carbon Phase from the Sludge Ponds at the Anzhersk Deposit
}

\author{
P. V. Sergeev and V. S. Beletskii \\ Donetsk National Technical University, Donetsk, Ukraine \\ e-mail: biletsk@i.ru \\ Received April 22, 2013
}

\begin{abstract}
The briquetting of coal slurries from the Anzhersk deposit in the Kuznets Basin is investigated. Petroleum binder and sodium lignosulfonate are employed. The solid carbon phase from the sludge ponds (ash content up to 35\%) has adequate briquetting properties when petroleum binder is added. The use of sulfite waste liquor at pressures of 80-100 MPa yields mechanically strong briquets that require additional water protection.
\end{abstract}

Keywords: coal slurry, briquetting, binder, briquet strength

DOI: $10.3103 / \mathrm{S} 1068364 \mathrm{X} 13080073$

Since the 1990s, the processing of coal slurry from coal-enrichment facility has been under active investigation. Today, processes available for this purpose include flotation, screw separation, and concentration on tables. The enrichment of coal fines from sludge ponds in hydraulic cyclones and inclined separators and by oil agglomeration are also being tested [1-5].

Globally, Canadian enterprises process coal slurry to extract a fuel, by means of modernized fixed or modular enrichment equipment. Briquetting is an effective and fairly inexpensive means of producing fuel from coal fines and may be used in the processing of carbon from sludge ponds [6].

In the present work, we investigate the briquetting of carbon material from slurry tanks at enrichment facilities in the Anzhersk deposit (Kuznets Basin).

We consider coal slurry from tanks in the Anzhersk deposit with the following characteristics: rank OS ( $V^{\text {daf }} 18.3 \%$ ); ash content of unenriched material $35.1 \%$; content of $<0.5-\mathrm{mm}$ class enriched by flotation $10.3 \%$. In flotation, the reagents are as follows: AAR collector, $2 \mathrm{~kg} / \mathrm{t}$; KOBS-150 foaming agent, $2 \mathrm{~g} / \mathrm{t}$; nonclinkering beads; piece size $0-2 \mathrm{~mm}(27.7 \%$ in the $<0.2 \mathrm{~mm}$ class and $4.3 \%$ in the $>2 \mathrm{~mm}$ class). The binders employed are BN-70 bitumen, Briketin, and sulfite waste liquor.

For briquetting, we use cylindrical matrixes (working-chamber diameter $25 \mathrm{~mm}$ ) in an IP-1 hydraulic press.

The preparation of the batch for briquetting with petroleum binder includes thermal drying and heating of the coal component to $80-90^{\circ} \mathrm{C}$; vigorous mixing of the coal with petroleum binder at $80-90^{\circ} \mathrm{C}$; batch cooling to $50-60^{\circ} \mathrm{C}$; and pressing of the batch at $25-$ $100 \mathrm{MPa}$. In investigating the briquetting properties of coal slurry with sulfite waste liquor, no heat treatment is employed.

The briquet strength is estimated from the limiting compressive strength. The briquets are fractured in the same hydraulic press, with recording of the destructive force. Two series of tests are conducted: with unenriched coal; and with a 2:1 mixture of the enriched coal and initial coal. The ash content of the batch is $26.7 \%$.

In Fig. 1, we show the briquetting properties of the unenriched slurry. Analysis shows that the strongest briquets (satisfying the requirements for domestic-fuel briquets) are obtained with $\mathrm{BN}-70$ bitumen as the binder. These briquets are produced with $7 \%$ binder, at $25 \mathrm{MPa}$ on roller presses. For stamping presses, at $80-$ $120 \mathrm{MPa}$, the BN-70 bitumen consumption may be reduced to $6 \%$.

The strength of the briquets obtained using Briketin is somewhat higher immediately after production but, after storage for a few days, the strength is better for the briquets based on bitumen. The strength of the briquets obtained with sulfite waste liquor is practically always less than that of the briquets based on petroleum products.

In Fig. 2, we show the briquetting properties of unenriched slurry and slurry enriched by flotation. Analysis indicates that the same trends are observed for the different binders. Introducing enriched mate- 
Binder: BN-70 bitumen
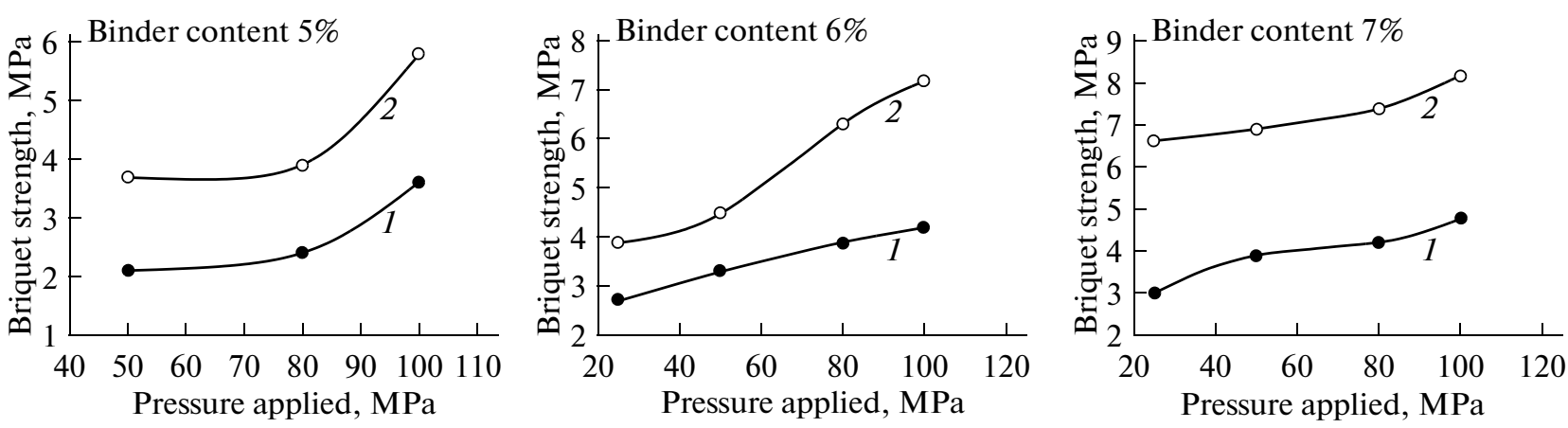

Binder: Briketin
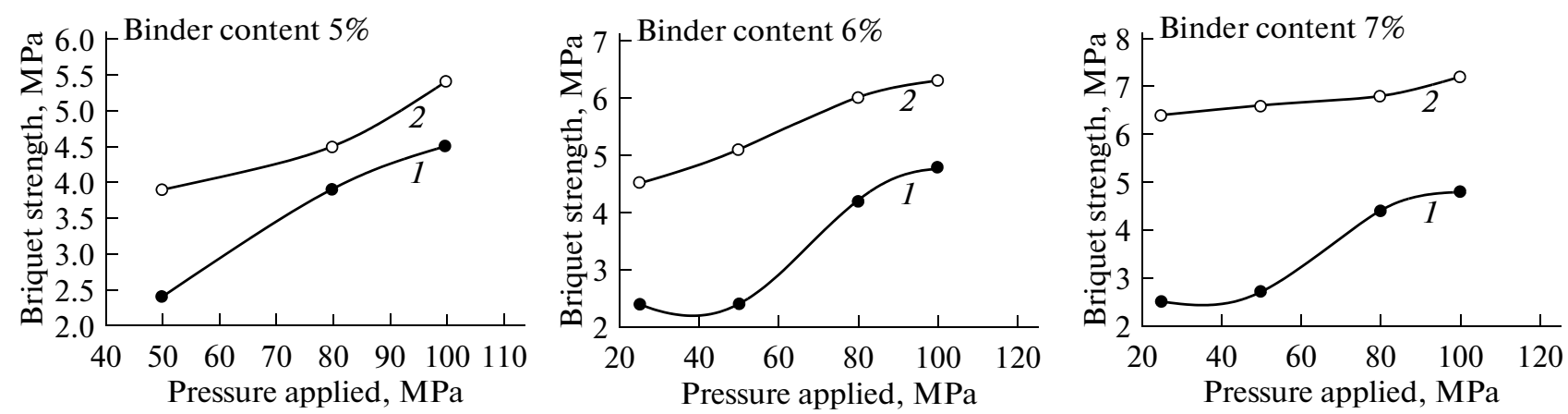

Binder: sulfite waste liquor
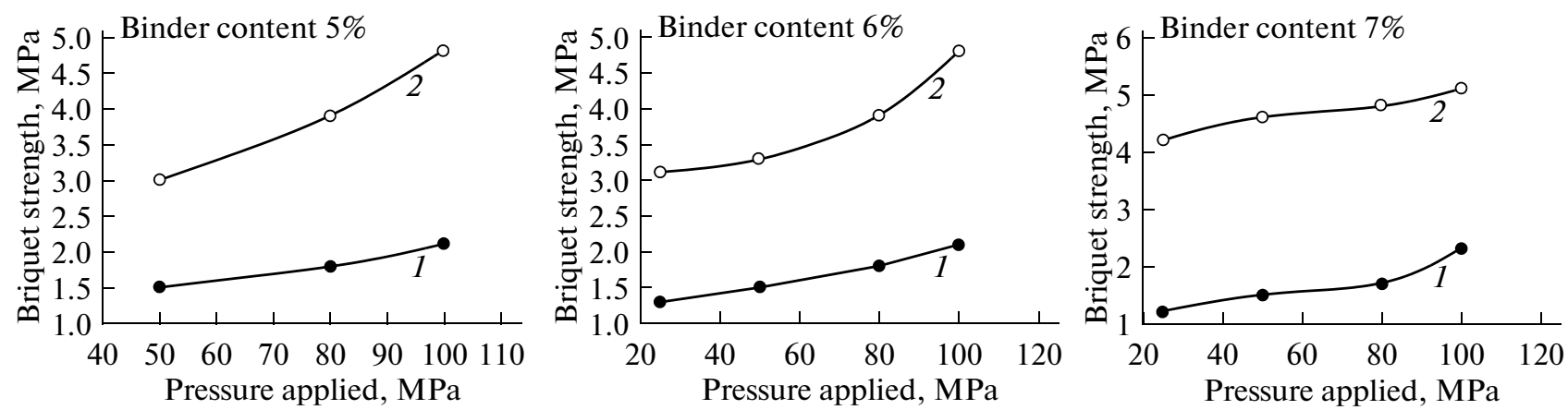

Fig. 1. Briquetting properties of unenriched coal slurry with different binders: (1) briquet strength 5 min after formation; (2) briquet strength $24 \mathrm{~h}$ after formation.

rial in the briquetting batch only slightly increases the strength of the briquets within the given range of ash content.

The briquet structure is studied by means of a Neophot-21 microscope in polished sections. In Fig. 3, we show a fragment of the briquet structure. We may see that the initial batch is well homogenized; there are no sections where the particle surface is not covered with binder. The relatively large particles do not break down, which indicates that pressing of the material is not excessive. Binding complexes are clearly seen in the intervals between individual coal particles. These complexes are substantial binder films, structured on account of filling by fine coal particles. That increases the strength of the briquets, since both internal and boundary binder layers are structured. 


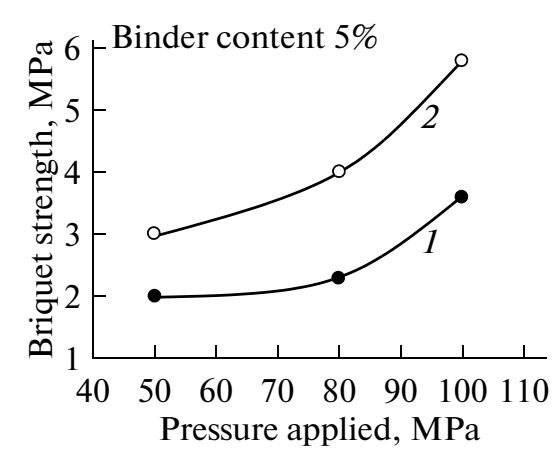

\section{Binder: BN-70 bitumen}
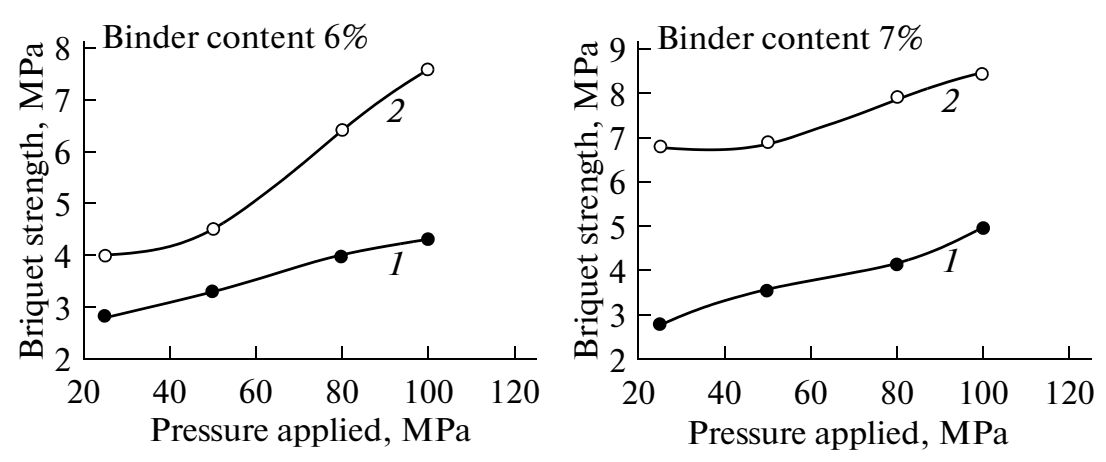

Binder: Briketin
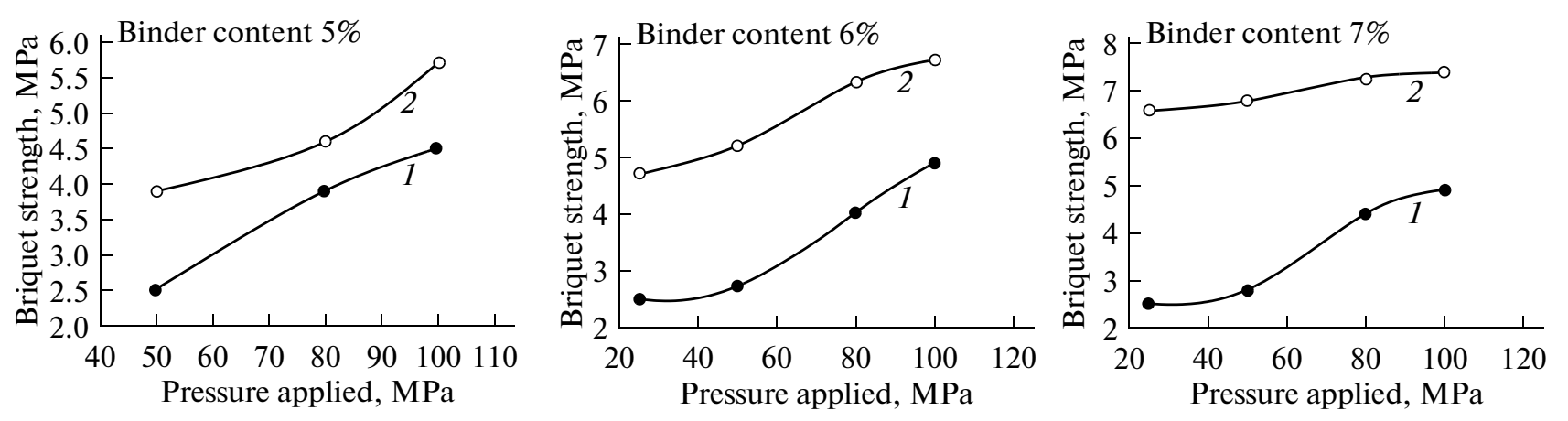

\section{Binder: sulfite waste liquor}
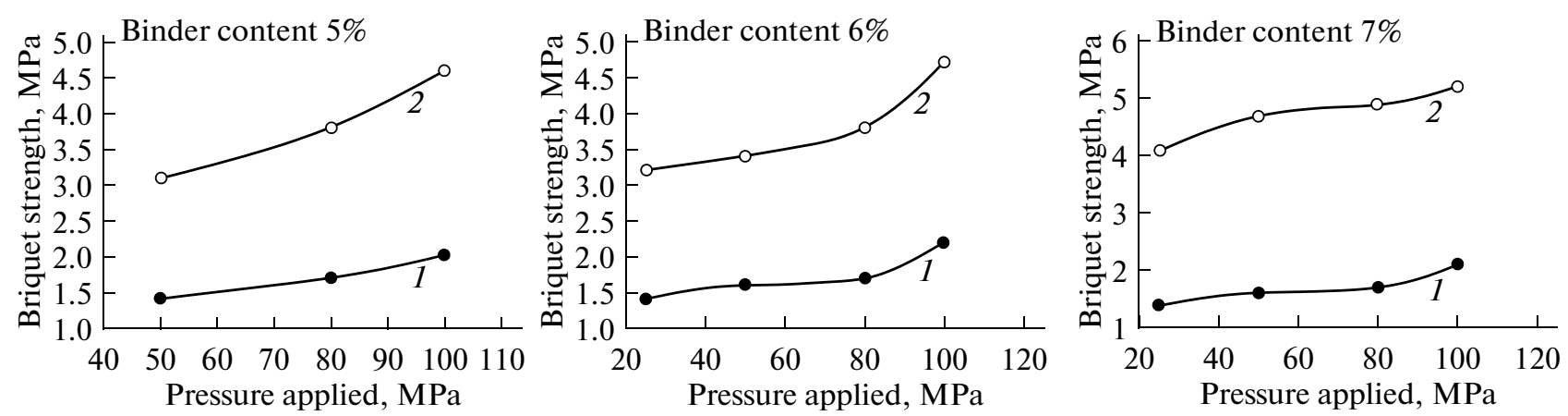

Fig. 2. Briquetting properties of a mixture of enriched and unenriched coal slurry with different binders: (1) briquet strength 5 min after formation; (2) briquet strength $24 \mathrm{~h}$ Fig. 3. Fragment of briquet structure: (1) individual coal grain; (2) carbon-binder complexes.

\section{CONCLUSIONS}

(1) The solid sludge of ash content up to $35 \%$ obtained from sludge ponds at enrichment facilities has adequate binding properties when petroleum binders are employed.

(2) The briquetting properties of batch containing a mixture of the initial slurry and the corresponding flotational concentrate improve when using petroleum binders: Briketin and BN-70 bitumen.

(3) In briquetting with sulfite waste liquor at 80$100 \mathrm{MPa}$, mechanically strong briquets may be obtained. However, their low water resistance entails additional expenses in organizing water protection on storage and transportation. Nevertheless, this process 


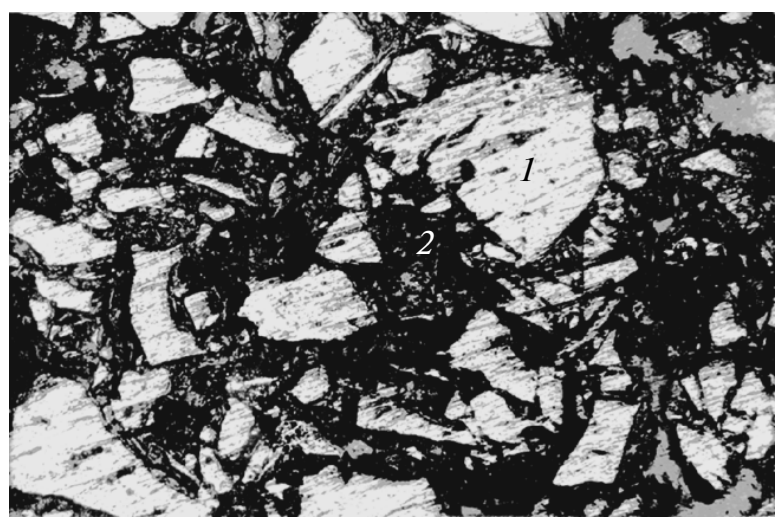

Fig. 3. Fragment of briquet structure: (1) individual coal grain; (2) carbon-binder complexes.

must be regarded as competitive on account of the lack of heat treatment in briquet production.

\section{REFERENCES}

1 1. Filipchenko, Yu.N., Morozova, L.A., Mavrenko, G.A., and Fedoseeva, S.O., Pererabotka otkhodov, soderzhashchikhsya $v$ ilonakopitelyakh (Processing of Waste from Sludge Pools), Lugansk: GP UkrNIIugleoborgashchenie, http://ukrnii.ucoz.ua/publ/pererabotka otkhodov_soderzhashhikhsja_v_ilonakopiteljakh/1-1$0-42$.

2. Saranchuk, V.I., Arovin, I.A., and Galushko, L.Ya., Flotirovanie uglei reagentami na produktov koksokhimii (Coal Flotation by Reagents from Coke-Plant Waste), Donetsk: Skhidnii Vidavnichii Dim, Kal'mius, 2006.

3. Kochetov, V.V., Levandovich, A.P., Berinberg, Z.Sh., et al., Using screw separators in coal enrichment, Zbag. Korisn. Kopal., 1998, no. 1(42), pp. 80-87.

4. Pilov, P.I., Kirnarskii, A.S., and Butenko, N.A., Waste slurry from enrichment facilities, Zbag. Korisn. Kopal., 1999, no. 5(46), pp. 3-9.

5. Garkushin, Yu.K., Sergeev, P.V., and Bilets'kii, V.S., Prospects for processing waste slurry, Zbag. Korisn. Kopal., 2003, no. 17(58), pp. 143-148.

6. Smirnov, V.O., Sergeev, P.V., and Bilets'kii, V.S., Tekhnologiya zbagacheniya vugillya (Coal-Enrichment Technology), Donetsk: Donets'kii Natsional'nii Tekhnichnii Universitet, Skhidnii Vidavnichii Dim, 2011.

Translated by Bernard Gilbert

SPELL: 1. ok 